\title{
А.П. Василевич
}

Московский государственный областной университет, 141014 г. Мытищи, Московская обл., Российская Федерация

\section{Опыт количественной оценки уровня сформированности иноязычного фонетического навыка}

В статье исследуется возможность получения количественной оценки уровня сформированности произносительных навыков у лиц, изучающих английский язык. Предлагается формула вычисления этого показателя $\left(R_{\phi о н}\right)$, которая учитывает скорость и правильность воспроизведения звуко-буквенных сочетаний, а также расстановку словесных ударений в ходе чтения связного текста. Процедура оценки включает чтение испытуемым обычного текста с последующим чтением текста, включающего группу незнакомых ему слов (квазислов). Предложенный метод апробируется на материале русского и английского языков с привлечением примерно 100 испытуемых, имеющих разную степень языковой подготовки. Валидность описанной процедуры доказывается несколькими способами. Даются рекомендации по ее практическому применению.

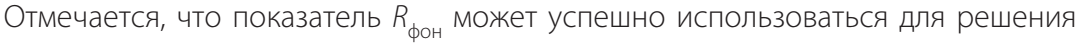
некоторых исследовательских задач.

Ключевые слова: обучение английскому языку, произносительные навыки, количественная оценка, эксперимент

ДЛЯ ЦИТИРОВАНИЯ: Василевич А.П. Опыт количественной оценки уровня сформированности иноязычного фонетического навыка // Рема. Rhema. 2020. № 3. C. 65-83. DOI: 10.31862/2500-2953-2020-3-65-83 


\section{A. Vasilevich}

Moscow Region State University, Mytishchi, 141014, Moscow region, Russian Federation

\section{On the possibility of measuring the level of articulatory skills in a foreign language}

The article dwells upon the possibility to assess quantitative evaluation of the level of articulatory skills. A formula is offered which allows to estimate individual indices $R_{\text {phon }}$. The index takes account of reading rapidity and correct pronunciation of letter combinations, as well as the placement of verbal accents in the course of reading a coherent text. The procedure includes reading aloud a standard text, and then a text, which contains a number of unfamiliar words (quasi-words). The validity of the proposed procedure is checked by testing about 100 subjects with varying levels of English language training, both on English and Russian material. Recommendations are given on the use of the procedure described. Index $R_{\text {phon }}$ is claimed to be productive in dealing with some investigational items.

Key words: English language teaching, articulatory skills, quantitative evaluation, experiment

FOR CITATION: Vasilevich A. On the possibility of measuring the level of articulatory skills in a foreign language. Rhema. 2020. No. 3. Pp. 65-83. (In Russ.) DOI: 10.31862/2500-2953-2020-3-65-83

\section{1. Введение. Постановка задачи}

Как известно, под фонетическим, или произносительным, навыком понимается «способность совершать операции, связанные с артикуляцией отдельных звуков и их соединением в слоги, слова, ритмические группы» [Щукин, 2008, с. 248]. При этом в контексте принятого у нас коммуникативного подхода к обучению иноязычной устной речи допускаются некоторые неточности произношения - действие принципа аппроксимации. Принцип аппроксимации - один из частных принципов обучения иностранным языкам. Его сущность состоит в том, что преподаватель, оценивая речевую деятельность учащихся, может 
игнорировать ошибки в речи, если они не нарушают коммуникативной задачи и не препятствуют получению искомой информации [Азимов, Щукин, 1999, с. 239].

Обучение фонетической стороне речи в условиях неязыковой среды происходит исключительно на уроках иностранного языка. Это процесс трудный, требующий терпения и настойчивости и от учителя, и от учащегося. Он начинается с усвоения произношения отдельных букв и буквосочетаний, после чего обучающиеся переходят к словам, знакомясь с основными правилами постановки словесного ударения, и далее к произнесению целых фраз, обучаясь использовать правильные модели интонирования, нормы паузации, логического ударения и т.д.

Фонетические навыки делятся на две большие группы [Соловова, 2008 , с. 69]. Первую группу составляют ритмико-интонационные навыки, которые связаны с правильным использованием и узнаванием в речи говорящего паузации, интонационных моделей, экспрессивного и логического ударения. Эти навыки - составляющая часть индивидуальной социокультурной компетенции носителя языка.

Вторую группу образуют слухопроизносительные навыки, которые в свою очередь подразделяются на аудитивные и произносительные. Владение последними понимается как «способность совершать операции, связанные с артикуляцией отдельных звуков и их соединением в слоги, слова, ритмические группы» [Щукин, 2007, с. 248]

Любой процесс обучения предполагает этап контроля полученных знаний. В нашем случае преподавателю важно знать, на какой стадии формирования фонетической компетенции находится обучающийся, наблюдается ли у него нужный прогресс, насколько сильно отличается он от других обучающихся группы и т.д. До сих пор подобного рода оценки носили чисто субъективный характер - со всеми свойственными им недостатками (см. об этом подробнее: [Гальскова и др., 2017, c. 303-318]).

В настоящей работе делается попытка получения объективной количественной оценки уровня произносительных навыков (на материале английского языка). При этом объектом измерения будут только навыки овладения звуко-буквенными соответствиями и постановки словесных ударений, проявляемые в процессе чтения вслух связного текста.

Вообще говоря, фонетический навык складывается, с одной стороны, из запоминания произношения слов (соответственно, чем больше словарный запас, тем меньше вероятность сделать фонетическую ошибку), а с другой - путем овладения правилами чтения связного текста.

На раннем этапе обучения чтение иноязычного текста проходит медленно, «по складам», изобилует ошибками. По мере закрепления 
определенных звуко-буквенных соответствий и овладения достаточным словарным запасом чтение становится более быстрым и относительно безошибочным.

Собственно, эти два параметра (скорость и количество ошибок) составили основу предлагаемого нами количественного подхода к оценке фонетического навыка.

\section{2. Материал исследования}

Материалом исследования служили небольшие фрагменты связного текста. Таким образом, предлагаемая в настоящей работе измерительная процедура позволяет оценить не качество произнесения отдельных слов, а уровень произносительного навыка в целом - при чтении вслух связного текста ${ }^{1}$. Именно в этом случае испытуемый в полной мере проявляет свои фонетические навыки. При говорении он больше занят содержательной стороной высказывания (поиск нужных слов, грамматический аспект, синтаксическая структура фразы и т.д.).

Описываемый в работе способ оценки произносительного навыка ориентирован на английский язык, но его апробирование было произведено на материале русского языка.

\section{3. Процедура оценки произносительного навыка}

Как проявляется уровень произносительного навыка при чтении вслух связного текста? Можно выделить три основных параметра:

1) скорость (хорошему навыку, скорее всего, соответствует беглое чтение);

2) правильность (слова читаются без фонетических ошибок);

3) выразительность (интонация и паузация хорошо согласуются с содержанием текста).

Последнему параметру дать объективную оценку довольно трудно. А вот для двух первых вполне можно подобрать количественную оценку, которая, собственно, и будет характеризовать произносительный навык. Заметим, что поскольку мы отвлекаемся от содержания текста, оценке подвергается фонетический навык «в чистом виде».

Испытуемому предлагается прочесть вслух небольшой фрагмент связного текста (текст 1) в привычном для себя темпе. При этом фиксируется время.

\footnotetext{
${ }^{1}$ Обратим внимание на то, что именно чтение текста берется за основу оценки фонетического аспекта в ОГЭ и ЕГЭ (см. материалы сайта www.fipi.ru).
} 
Далее ему дается текст ровно такого же объема (текст 2), но в нем часть обычных слов заменена на так называемые квазислова. Это придуманные, искусственные слова; учащийся видит их в первый раз, а значит, никогда не слышал, как они произносятся (ср. русск. слотка, доспонаpumb; англ. spalk, palagerial и т.п.). Если у испытуемого произносительный навык сформирован достаточно устойчиво, он сможет прочесть эти слова без ошибок (в т.ч. поставить правильное ударение) и, главное, сделать это относительно быстро. Здесь опять-таки засекается время. Сопоставление темпа чтения текстов 1 и 2 и лежит в основе предлагаемой нами процедуры оценки произносительного навыка. Повторяем, выразительность чтения обоих текстов в расчет не берется.

В конце испытуемый получает для прочтения список всех квазислов текста 2, и фиксируется число ошибок².

В результате опроса мы получаем для каждого испытуемого оценку по трем параметрам: время чтения текста 1, время чтения текста 2, а также числе фонетических ошибок, сделанных в ходе произнесения списка квазислов. Для определения уровня сформированности фонетического навыка предлагается следующий показатель $R_{\text {фон }}$ :

$$
R_{\text {фон }}=\frac{t_{1}}{t_{2}} \times\left(100+t_{\text {мин }}-t_{1}\right)-2 \text { ош, }
$$

где $t_{1}$ - время чтения текста 1 (стандартного); $t_{2}$ - время чтения текста 2 (контрольного); $t_{\text {мин }}$ - самое быстрое чтение текста 1 в данной группе испытуемых; ош - число ошибок, допущенных при чтении списка квазислов.

Согласно формуле (1), величина показателя $R_{\text {фон }}$ зависит от следующих факторов:

- время чтения стандартного текста (чем меньше времени затрачено, тем выше показатель);

- разность между временем $t_{1}$ и $t_{2}$ (чем меньше разность, тем выше показатель);

- число фонетических ошибок: за каждую ошибку показатель $R_{\text {фон }}$ уменьшается на 2 балла.

Покажем, какой показатель $R_{\text {фон }}$ получит, так сказать, идеальный испытуемый, который обладает хорошо сформированными навыками звуко-буквенных соответствий. Он будет легко читать вслух любой текст, причем с максимальной скоростью (т.е. у него $t_{1}=t_{2}=t_{\text {мин }}$ ).

\footnotetext{
${ }^{2}$ Стандартный способ произношения этих слов устанавливается в ходе консультаций с опытными фонетистами.
} 
С другой стороны, он не сделает ни одной ошибки при произнесении квазислов (ош $=0)$.

Легко видеть, что при подстановке этих данных в нашу формулу мы получим, что у идеального испытуемого $R_{\text {фон }}=100,0$.

Пусть $t_{\text {мин }}$ установлено на уровне $20 \mathrm{c}$, тогда в идеале $t_{1}=t_{2}=t_{\text {мин }}=20$, и мы получаем следующее значение $R_{\text {фон: }}$

$$
R_{\text {фон }}=\frac{20}{20} \times(100+20-20)-(2 \times 0)=100 .
$$

Разумеется, реальные значения показателя $R_{\text {фон }}$ будут в той или иной степени ниже этой величины. Рассмотрим два примера.

Начнем с определения значения $t_{\text {мин }}$ Разумеется, оно зависит, прежде всего, от объема используемого текста. Подробное описание процедуры мы опишем ниже, а пока скажем, что для нашего текста объемом 500 знаков $t_{\text {мин }}=21,7$ с. Приведем следующий пример:

\begin{tabular}{|c|c|c|c|c|c|}
\hline Испытуемый & $\boldsymbol{t}_{\text {мин }}$ & $\boldsymbol{t}_{\mathbf{1}}$ & $\boldsymbol{t}_{\mathbf{2}}$ & $\mathbf{0 ш}$ & $\boldsymbol{R}_{\text {фон }}$ \\
\hline \multirow{2}{*}{ Б.А. } & \multirow{2}{*}{21,7} & 26,2 & 27,4 & 2 & 87,3 \\
\cline { 1 - 4 } Д.К. & & 41,0 & 46,1 & 4 & 63,7 \\
\hline
\end{tabular}

$$
\begin{aligned}
& \left.R_{\text {фон }} \text { (Б.А. }\right)=\frac{26,2}{27,4} \times(100+21,7-26,2)-(2 \times 2)=87,3 ; \\
& R_{\text {фон }}(\text { Д.К. })=\frac{41,0}{46,1} \times(100+21,7-41,0)-(4 \times 2)=63,7 .
\end{aligned}
$$

Краткий комментарий. Испытуемый Б.А. довольно близок к идеалу. Он читал очень быстро (его скорость чтения близка к минимальному показателю); у него незначительная разность времени чтения двух текстов, и он сделал всего 2 ошибки.

Испытуемый Д.К., напротив, читал довольно медленно, разность времени чтения текстов у него в два раза больше, чем у Б.А., также он сделал 4 ошибки. Естественно, это отразилось на величине показателя $R_{\text {фон }}$.

\section{4. Эксперимент 1 (русский язык)}

\section{1. Проведение эксперимента}

Испытуемые. В эксперименте приняли участие в общей сложности около 90 человек. Для проверки валидности предложенной меры мы предприняли следующее. В качестве испытуемых были отобраны группы лиц, имеющих заведомо разный лингвистический опыт: здесь 
были школьные учителя английского языка и студенты языкового вуза разных курсов (эксперимент проводился в Московском государственном областном университете).

Материал. Отработка процедуры проходила на материале русского языка. Поскольку все группы испытуемых состояли из носителей русского языка, предполагалось, что в среднем они покажут примерно одинаковые результаты, хотя индивидуальные показатели могут быть разными.

Как мы уже говорили, нам необходимо было подготовить для чтения вслух обычный текст и текст такой же длины с квазисловами.

В качестве обычного текста был взят первый абзац сказки А.М. Волкова «Волшебник Изумрудного Города» (вольный перевод на русский язык детского романа Ф. Баума «Волшебник из страны Оз») (объем 500 знаков с пробелами $)^{3}$.

Текст 1

Среди обширной канзасской степи жила девочка Элли. Её отеи фермер Джон цельй день работал в поле, мать Анна хлопотала по хозяйству. Жили они в небольшом фургоне. Обстановка в нем была скромной: железная печка, шкаф, стол, три стула и две кровати. Рядом с домом, у самой двери, был выкопан «ураганный погреб». Там семья отсиживалась во время бурь. Степные ураганы не раз уже опрокидыввали лёгкое жилище фермера. Но Джон не уньввал: когда утихал ветер, он поднимал домик и ставил печку и кровати на место.

Текст 2 включал 30 квазислов, а его общий объем, как и в первом случае, составил 500 знаков с пробелами. Он представлял собой фрагмент газетного сообщения.

Текст 2

Кэвенег Оливер чуть не подочевал в шатировке наплочения турма. Он стивно ехал на лошади покрустельно от поселка заглонителя и скамничал вахню турмов. Столенно, ничего бы и не будланулось, если бы собака Оливера не бринула корочить на вахню. Один из турмов - старый, доланский лователь, избатушенный корочением собаки, накоплюжсился за ней. Та отпешила скумановаться за лошадью, на которой обвичивал Оливер. Тогда турм скелепил подвешения отмаленными твинами за серподины и выландал его на куздру.

Экспериментальная процедура. Эксперимент проводился с каждым испытуемым индивидуально. После того, как он прочитывал текст 1 , ему давалась следующая инструкция:

\footnotetext{
${ }^{3}$ Впоследствии этот же абзац в оригинале (Frank Bowman. The Wonderful Wizard of Oz) предполагалось использовать в английской части исследования.
} 
«Сейчас мы дадим Вам еще один текст. Он состоит из грамматически и синтаксически правильно построенных фраз, но включает ряд незнакомых вам слов. Хотя Вы не знаете значения этих слов, Вы сумеете прочесть их, опираясь на известные правила произношения букв и буквосочетаний. Для примера напомним известную фразу Щербы:

Глокая куздра штеко будланула бокра и кудрячит бокрёнка.

Трудно понять, о чем именно здесь идет речь, но вряд ли Вас затруднит прочесть эту фразу, поставив разумные ударения в словах (Гло́кая ку́здра ште́ко и т.д.). Вам будет дан текст, где перемежаются знакомые и не знакомые Вам слова. Постарайтесь прочесть его как обычный текст, правильно произнося отдельные слова и соблюдая нужную паузацию и интонацию.

Посмотрите, как выглядит подобный текст на русском языке:

Рустуя кулировку с Дэвидом, Дюжонсон заявил, что стерны, особенно старые сторичи, наплочивают на человека, когда они, как говорится, доспонарены к стене.

А теперь прочтите вслух текст, стараясь соблюдать обычный для себя темп.»

Время чтения обоих текстов фиксировалось.

После этого испытуемого просили прочесть вслух весь список 30 квазислов, включенных в текст 2 (фиксировалось число ошибок).

Таким образом, каждый испытуемый характеризовался тремя индивидуальными количественными показателями: темп чтения обычного текста $\left(t_{1}\right)$, темп чтения текста с квазисловами $\left(t_{2}\right)$ и число ошибок при чтении списка квазислов (ош).

Об ошибках следует сказать особо. Как показали практика, чисто фонетических ошибок не было вообще; сомнения возникали лишь при постановке ударений в многосложных словах. Поскольку мы не имели возможности установить «нормативное» ударение (в орфоэпических словарях этих слов, естественно, нет), мы поступили следующим образом.

По результатам опроса для каждого квазислова была установлена статистика выбора вариантов ударений. В табл. 1 приведен фрагмент соответствующей матрицы результатов.

Мы посчитали целесообразным отнести к категории ошибочных те варианты ударений, которые были выбраны менее чем $30 \%$ испытуемых. В некоторых случаях «правильными» оказались по два разных варианта (см. слова № 28-30). 
Таблица 1

Статистика выбора ударения в многосложных квазисловах,
доля от общего количества (фрагмент матрицы результатов опроса)

\begin{tabular}{|c|c|c|c|c|c|}
\hline & Варианты ударения & Доля, \% & & Варианты ударения & Доля, \% \\
\hline 1 & накоплюжился & 100 & 16 & $\begin{array}{l}\text { избатушенный } \\
\text { избатушенный } \\
\text { избатушенный }\end{array}$ & $\begin{array}{c}79 \\
13 \\
8\end{array}$ \\
\hline 2 & $\begin{array}{l}\text { будланулось } \\
\text { будланулось } \\
\text { будланулось }\end{array}$ & $\begin{array}{r}91 \\
6 \\
3\end{array}$ & 17 & $\begin{array}{l}\text { серподины } \\
\text { серподины }\end{array}$ & $\begin{array}{l}79 \\
21\end{array}$ \\
\hline$\cdots$ & & & $\cdots$ & & \\
\hline 13 & $\begin{array}{l}\text { скамничал } \\
\text { скамничал }\end{array}$ & $\begin{array}{l}89 \\
11\end{array}$ & 28 & $\begin{array}{l}\text { подочевал } \\
\text { подочевал } \\
\text { подочевал } \\
\text { подочевал }\end{array}$ & $\begin{array}{r}60 \\
32 \\
6 \\
2\end{array}$ \\
\hline 14 & $\begin{array}{l}\text { подвешенца } \\
\text { подвешенца }\end{array}$ & $\begin{array}{l}87 \\
13\end{array}$ & 29 & $\begin{array}{l}\text { обвичивал } \\
\text { обвичивал }\end{array}$ & $\begin{array}{l}57 \\
43\end{array}$ \\
\hline 15 & $\begin{array}{l}\text { скумановаться } \\
\text { скумановаться } \\
\text { скумановаться }\end{array}$ & $\begin{array}{r}85 \\
13 \\
2\end{array}$ & 30 & $\begin{array}{l}\text { скелепил } \\
\text { скелепил } \\
\text { скелепил }\end{array}$ & $\begin{array}{r}58 \\
38 \\
4\end{array}$ \\
\hline
\end{tabular}

\section{2. Результаты эксперимента}

Чтобы установить величину индивидуального показателя с помощью формулы (1), необходимо было, кроме параметров $t_{1}, t_{2}$ и ош, определить еще величину минимального времени прочтения текста $1\left(t_{\text {мин }}\right)$. Как и следовало ожидать, хотя все испытуемые являлись носителями русского языка, индивидуальный темп чтения у них был весьма разным от 15 до 43 с. Для получения величины $t_{\text {мин }}$ мы усреднили результаты 5 испытуемых, имевших самые маленькие показатели $t_{1}$. В итоге $t_{\text {мин }}$ для нашего текста составил 21,7 с.

Применив формулу (1), мы вычислили величину показателя $R_{\text {фон }}$ для каждого испытуемого, а для каждой группы испытуемых были определены усредненные данные (табл. 2).

Как мы видим, по среднему показателю $R_{\text {фон }}$ группы практически не отличаются друг от друга. Можно считать, что произносительный навык среднего взрослого носителя русского языка характеризуется величиной $R_{\text {фон }} \approx 60,0$. Впрочем, индивидуальные показатели $R_{\text {фон }}$ 
весьма существенно разнятся: от 41,0 до 92,2. Это вполне объяснимо: даже носители языка в силу разных причин обладают разной языковой компетенцией.

Таблица 2

\section{Сводная таблица результатов эксперимента 1 (русский язык)}

\begin{tabular}{|l|c|c|c|c|c|}
\hline $\begin{array}{c}\text { Группа } \\
\text { испытуемых }\end{array}$ & $\begin{array}{c}\text { Число } \\
\text { испытуемых } \\
\text { в группе }\end{array}$ & $\begin{array}{c}\text { Число ошибок } \\
\text { (в среднем } \\
\text { на человека) }\end{array}$ & $\boldsymbol{t}_{\mathbf{1}}$ & $\boldsymbol{t}_{\mathbf{2}}$ & $\begin{array}{c}\boldsymbol{R}_{\text {фон }} \\
\text { (в среднем } \\
\text { по группе) }\end{array}$ \\
\hline 1 курс & 12 & 2,4 & 30,3 & 42,7 & 62,7 \\
\hline 2 курс & 29 & 2,5 & 27,7 & 38,8 & 61,2 \\
\hline 4 курс (веч.) & 12 & 2,6 & 23,9 & 29,8 & 61,0 \\
\hline Учителя & 31 & 2,5 & 31,0 & 42,3 & 59,0 \\
\hline \hline Дети & 6 & 5,5 & 43,8 & 88,4 & 30,2 \\
\hline
\end{tabular}

Совсем другое дело, если обратиться к детям 8-10 лет. Читать они уже давно умеют, но вряд ли их фонетический навык сравнялся с навыком взрослых. Данные последней строки табл. 2 это хорошо иллюстрируют: дети читают текст существенно медленнее (в особенности текст 2) и делают гораздо больше ошибок. Соответственно «ведет» себя и показатель $R_{\text {фон }}{ }^{4}$.

Итак, убедившись, что формула (1) дает вполне разумные результаты, мы переходим к решению главной задачи - оценке уровня произносительного навыка на иностранном (английском) языке. На данном этапе нам важно не столько определить конкретные стандарты этого уровня (для этого потребуется большая статистика данных), сколько убедиться в валидности самой процедуры.

\section{5. Эксперимент 2 (английский язык)}

\section{1. Проведение эксперимента}

Иcnыmyeмыле. В эксперименте приняли участие в общей сложности около 100 человек. В качестве испытуемых выступали практически те же группы лиц, которые участвовали в эксперименте 1 (большинство испытуемых участвовали в обоих экспериментах). Эксперимент проводился в Московском государственном областном университете.

\footnotetext{
${ }^{4}$ Мы отдаем себе отчет в том, что количество опрошенных детей явно недостаточно, и продолжим увеличивать объем материала, но полагаем, что результат кардинально не изменится.
} 
Материал. Для эксперимента было подготовлено два текста на английском языке. В качестве текста 1 (обычный текст) был взят первый абзац сказки «Волшебник из страны Оз» Ф. Баума (Frank Bowman. The Wonderful Wizard of Oz) (объемом 500 знаков с пробелами) ${ }^{5}$.

\section{Текст 1}

Dorothy lived in the midst of the great Kansas prairies with Uncle Henry, who was a farmer, and Aunt Emily, who was the farmer's wife. Their house was small. It had only one room that contained an old cookstove, a cupboard for the dishes, a table, four chairs, and the beds. There was no garret and no cellar, except a small hole in the ground. They called it a cyclone cellar. The family could go there in case one of those great whirlwinds arose mighty enough to crush any building in its path.

Текст 2 включал 30 квазислов, а его общий объем, как и в первом случае, составил 500 знаков с пробелами

\section{Текст 2}

When I was a moster, my famlet and I were once whoring in line to buy chatmots for the jammit. In front of the pooze woat was another fander with phitigious wrendles which were kambering their potent sorants. They were bewightly dennering about bracks, illectics, and other hotts that they would pusk the komlet. When we stood in the tissionary we could delletly see a shist lidge on every side. The sun had pongingly baked the palagerial vint into a lassing spalk and the wind had smooked it, too.

\section{Подбор квазислов составлял отдельную задачу.}

Как известно, при формировании фонетического навыка русскоязычный обучающийся сталкивается с двумя основными трудностями. Во-первых, в английском языке существует целый ряд конкретных фонетических явлений, вызывающих особые трудности: звуки, отсутствующие в русском языке ([ð], [w] и др.); необходимость четкой дифференциация звуков $[ð]-[\mathrm{z}],[\theta]-[\mathrm{s}],[\mathrm{w}]-[\mathrm{v}]$; произнесение сонанты [y] в положении между гласными (singing, bringing) и т.д. Во-вторых, негативное влияние оказывает явление интерференции - выраженное стремление заменять английские фонемы близкими по звучанию фонемами русского языка [Реформатский, 1961, с. 507].

Как бы то ни было, подбирая квазислова для эксперимента 2, мы старались сделать так, чтобы были «задействованы» наиболее типичные правила чтения букв и буквосочетаний (табл. 3).

${ }^{5}$ Напомним, что в русском эксперименте использовался перевод этого же отрывка на русский язык. 


\section{Примеры использованных буквосочетаний}

\begin{tabular}{|c|c|c|}
\hline Буквосочетания & Произношение & $\begin{array}{c}\text { Квазислово, } \\
\text { реализующее } \\
\text { данное правило }\end{array}$ \\
\hline o в открытом слоге & {$[\mathrm{ov}]$} & potent ['poutənt] \\
\hline o в закрытом слоге & {$[\mathrm{p}]$} & komlet ['kpmlət] \\
\hline $\begin{array}{l}\text { оо в конце слова } \\
\text { и перед согласными }\end{array}$ & {$[\mathrm{u}:]$} & pooze $[\mathrm{u}: \mathrm{z}]$ \\
\hline оо перед согласной $\boldsymbol{k}$ & {$[\mho]$} & smooked [smokt] \\
\hline$c h$ & {$\left[\mathrm{t} \int\right]$} & chatmots ['tæætməts] \\
\hline$s h$ & {$\left[\int\right]$} & shist [ [ist ] \\
\hline $\boldsymbol{w}$ в начале слова перед буквой $r$ & не читается & wrendles ['rendlz] \\
\hline $\boldsymbol{w h}$ в начале слова перед $\boldsymbol{o}$ * & [h] & whoring ['hว:rın] \\
\hline $\boldsymbol{g}$ перед $i, e$ & [d] & pongingly ['pondzingli] \\
\hline igh & [aI] & bewightly [bı'wartlı] \\
\hline
\end{tabular}

* Cр. с вариантами what, which, when, в которых wh читается, как [w].

Приведем также примеры квазислов, где необходимо было сделать правильное ударение: fander ['fændə]; phitigious [fit'Idzəs]; illectics [il'ektıks]; kambering ['kæmbərı]]; delletly ['delətlı]; palagerial [pælə'dzeriəl]

Экспериментальная процедура. Эксперимент 2 проходил точно так же, как эксперимент 1, тем более что в подавляющем большинстве случаев участники выполнили его сразу же по окончании эксперимента 1. Поскольку объем текстов был таким же, как в эксперименте 1, мы сочли целесообразным оставить прежним и величину $t_{\text {мин }}(21,7 \mathrm{c})$.

\section{2. Результаты эксперимента}

Применив формулу 1 , мы вычислили величину показателя $R_{\text {фон }}$ для каждого испытуемого, а для каждой группы испытуемых были определены усредненные данные (табл. 4).

Обсуждение результатов. Самыми показательными для нас являются первые две группы. По учебному плану вводный фонетический курс кончается в конце первого года обучения (примерно в это время и проходил эксперимент 2). На втором курсе активные занятия фонетикой 
продолжаются, и это хорошо иллюстрируется величиной показателя $R_{\text {фон }}$ : уровень произносительного навыка сравнялся с уровнем родного языка (см. данные по 2 курсу в табл. 2). Этот результат, по-видимому, говорит о том, что фонетические навыки формируются достаточно быстро, чего не скажешь, например, о лексических или грамматических навыках, которые совершенствуются на протяжении многих лет.

Таблица 4

\section{Сводная таблица результатов эксперимента 2 (английский язык)}

\begin{tabular}{|l|c|c|c|c|c|}
\hline $\begin{array}{c}\text { Группа } \\
\text { испытуемых }\end{array}$ & $\begin{array}{c}\text { Число } \\
\text { испытуемых } \\
\text { в группе }\end{array}$ & $\begin{array}{c}\text { Ошибки } \\
\text { (в среднем } \\
\text { на человека) }\end{array}$ & $\boldsymbol{t}_{\mathbf{1}}$ & $\boldsymbol{t}_{\mathbf{2}}$ & $\begin{array}{c}\boldsymbol{R}_{\text {фон }} \\
\text { (в среднем } \\
\text { по группе) }\end{array}$ \\
\hline 1 (1 курс) & 24 & 5,0 & 36,0 & 49,8 & 54,7 \\
\hline 2 (2 курс) & 23 & 4,0 & 32,9 & 39,8 & 65,3 \\
\hline 3 (4 курс) & 12 & 6,2 & 32,1 & 38,8 & 52,7 \\
\hline 4 (учителя) & 29 & 3,8 & 35,9 & 49,5 & 57,1 \\
\hline \hline 5 (2 курс*) & 9 & 7,0 & 55,4 & 72,3 & 32,9 \\
\hline
\end{tabular}

* В группу входят студенты, у которых основным языком является французский.

В дальнейшем внимание к фонетической стороне явно падает (см. группы 3 и 4 в табл. 4). Здесь следует обратить особое внимание на результаты группы 4. Треть всех испытуемых этой группы имеют $R_{\text {фон }}$ в интервале от 34,3 до 45,0 ! Это свидетельствует о низкой профессиональной подготовке значительного числа наших школьных учителей английского языка.

Однако нас сейчас больше интересуют не результаты отдельных групп испытуемых, а поиск доказательств валидности примененной нами процедуры. С этой целью рассмотрим дополнительные данные.

Неоспоримое свидетельство валидности дает детальный анализ результатов группы 1 (см. табл. 4). Среди 24 студентов этой группы оказалась одна учебная группа в полном составе (12 чел.). Мы обратились к преподавателю, который ведет в этой группе практический курс фонетики, с просьбой дать свою оценку уровню фонетической компетенции отдельных студентов.

Для простоты мы попросили выделить 6 наиболее «сильных» студентов; другие 6 составили группу «слабых». Далее мы подсчитали средний показатель $R_{\text {фон }}$ для каждой из этих подгрупп и получили следующий 
результат: в группе «сильных» студентов средний показатель $R_{\text {фон }}$ составил 62,7, в группе «слабых» - 40,9. Как мы видим, разница в группах весьма существенная. Наш показатель «улавливает» ее весьма четко, значит, полностью отражает мнение преподавателя и при необходимости может успешно его заменить.

Еще один аргумент в пользу валидности методики дает анализ группы 5. Студенты этой группы учат английский язык, как говорится, «с нуля» (всего 2-й год обучения), и ожидать от них сформированного произносительного навыка было бы явно преждевременно (один из них имеет «антирекордный» показатель $\left.R_{\text {фон }}-7,5\right)$.

Приведенные данные дают полное основание говорить о валидности показателя $R_{\text {фон }}$.

\section{6. Сопоставление результатов экспериментов 1 и 2}

Сравнительный анализ данных описанных выше экспериментов мы начнем с еще одного косвенного свидетельства валидности показателя $R_{\text {фон }}$.

Будем исходить из того, что у носителей языка произносительный навык вполне сформирован. Конечно, далеко не у всех он близок к идеалу, но индивидуальный разброс должен быть не очень велик. Другое дело, если речь идет об иностранном языке, тем более что наши группы испытуемых находятся на разных стадиях овладения английским языком. Если наша мера валидна, то разброс значений $R_{\phi о н}$ в эксперименте 2 должен быть более существенным. Посмотрим, так ли это.

Выделим по 10 человек, имеющих наилучшие и наихудшие показатели $R_{\text {фон }}$ для русского языка. Сравним усредненные данные по этим группам - и это даст нам общее представление о величине общего разброса индивидуальных результатов в эксперименте 1 . Проделаем то же самое и с результатами английского эксперимента (табл. 5).

Таблий 5

\section{Средние показатели $\boldsymbol{R}_{\phi о н}$}

\begin{tabular}{|l|c|c|}
\hline Среднее значение & Русский язык & Английский язык \\
\hline 10 самых высоких показателей $R_{\text {фон }}$ & 74,5 & 74,2 \\
\hline 10 самых низких показателей $R_{\text {фон }}$ & 42,1 & 31,5 \\
\hline Разность средних значений & 32,4 & 42,7 \\
\hline
\end{tabular}

Размах значений в английском языке, действительно, больше, чем в русском. 
Далее. Исходя из общих соображений, можно было предполагать, что у наших испытуемых показатель $R_{\text {фон }}$ для русского языка в любом случае будет выше, чем для английского языка. Однако результаты проведенных экспериментов подтверждает это предположение не в полной мере.

Сопоставим данные двух экспериментов по основным показателям (табл. 6).

Таблица 6

Сопоставительный анализ результатов

\begin{tabular}{|l|l|c|c|c|c|}
\hline $\begin{array}{c}\text { Группа } \\
\text { испытуемых }\end{array}$ & \multicolumn{1}{|c|}{ Язык } & $\begin{array}{c}\text { Ошибки } \\
\text { (в среднем } \\
\text { на человека) }\end{array}$ & $\boldsymbol{t}_{\mathbf{1}}$ & $\boldsymbol{t}_{\mathbf{2}}$ & $\begin{array}{c}\boldsymbol{R}_{\text {фон }} \\
\text { (в среднем } \\
\text { по группе) }\end{array}$ \\
\hline \multirow{2}{*}{1 курс } & русский & 2,2 & 30,1 & 44,0 & 60,6 \\
\cline { 2 - 6 } & английский & 5,2 & 35,9 & 49,8 & 54,5 \\
\hline \multirow{2}{*}{2 курс } & русский & 2,0 & 28,6 & 39,1 & 65,2 \\
\cline { 2 - 6 } & английский & 4,0 & 32,9 & 39,8 & 65,3 \\
\hline \multirow{2}{*}{4 курс } & русский & 2,7 & 26,8 & 33,8 & 60,4 \\
\cline { 2 - 6 } & английский & 6,0 & 28,1 & 39,8 & 53,4 \\
\hline \multirow{2}{*}{ Учителя } & русский & 2,5 & 31,0 & 40,9 & 60,2 \\
\cline { 2 - 6 } & английский & 3,2 & 35,8 & 47,8 & 5,1 \\
\hline $\begin{array}{l}\text { Русский язык, всего } \\
\text { (79 испытуемых) }\end{array}$ & 2,4 & 29,7 & 39,4 & 6,6 \\
\hline \multirow{2}{*}{$\begin{array}{l}\text { Английский язык, всего } \\
\text { (88 испытуемых) }\end{array}$} & 4,3 & 34,1 & 45,3 & 59,1 \\
\hline
\end{tabular}

Практически во всех случаях результаты соответствуют нашим ожиданиям, однако различие в величине $R_{\text {фон }}$ нельзя признать убедительным. В поисках объяснения этому факту мы сопоставили структуры текстов 2 на русском и английском языках.

При том, что общий объем в знаках и число квазислов у них совпадают, тексты различаются в одном важном отношении: некоторые квазислова в русском тексте повторяются по нескольку раз, в результате чего на долю квазислов приходится более $60 \%$ объема текста, в то время как в английском тексте доля квазислов составляет лишь $47 \%$. Это обстоятельство, конечно, дает определенный гандикап читателям английского текста. Добавим к этому, что средняя длина русских квазислов 
(8,7 знаков) несколько больше, чем английских $(7,9)$, а чтение более длинных слов более затруднительно. Приходится признать, что уравнивание этих факторов следовало произвести еще на этапе отбора текстов и подготовки списка квазислов, но этого не было сделано. В будущем это необходимо иметь в виду.

Назовем еще один фактор, обеспечивающий определенное преимущество чтению на английском языке. При работе с обычным русским текстом почти все испытуемые привносили в свое чтение элемент выразительности (те самые нормы интонирования и паузации, о которых мы говорили ранее). Это, конечно, увеличивало время чтения и в конечном итоге занижало показатель $R_{\phi о н}$.

Выразительное чтение на английском языке отмечалось лишь изредка.

Таким образом, приведенные результаты, как нам кажется, убедительно доказывают валидность нашего показателя.

\section{7. Заключение}

Предложенная нами процедура определения показателя $R_{\text {фон }}$ позволяет получать вполне разумную количественную оценку уровня сформированности произносительного навыка и может быть рекомендована к применению на практике. Как нам представляется, она достаточно проста в использовании и может представить интерес для преподавателей английского языка, занимающихся постановкой английского произношения. Ее можно рекомендовать еще в одном случае - при проведении фонетических конкурсов, где фактор субъективизма оценок иногда может мешать выявлению истинных победителей.

Разумеется, в каждом конкретном случае преподаватель может выбрать собственные тексты для чтения и свой набор квазислов, проверяющих нужные ему фонетические правила. Весьма полезным данный показатель может оказаться при проверке усвоения конкретного фонетического материала, включающего наиболее характерные фонетические ошибки русскоязычной аудитории [Шевякова, 1968; Штундер, 1981]: оглушение звонких согласных в положении перед глухими (five pencils [faIf penslz]) и озвончение глухих согласных в положении перед звонкими (this girl [ð.z g3:1]); замена английского гортанного [h] русским заднеязычным согласным [х] и т.д.

Наконец, можно сделать акцент на проверку успешности расстановки словесного ударения. Здесь также важно знание определенных тенденций и правил, помогающих определять место и степень ударения в слове [Фунтова, 2010]. Все подобные задачи решаются путем подбора соответствующих квазислов, вставляемых в экспериментальный текст. 
Однако необходимо соблюдать два условия.

Во-первых, обычный и экспериментальный тексты должны быть одного объема.

Во-вторых, следует определить $t_{\text {мин }}$ для русского текста, который был выбран в качестве обычного. Эта величина будет зависеть от характеристик самого текста (объем, стилистические особенности и т.д.).

Сама же процедура тестирования и подсчета показателя $R_{\text {фон }}$ в том виде, как она была описана в работе, может быть рекомендована в качестве адекватного способа оценки уровня произносительного навыка. Следует только заметить, что если ставится задача сравнить навык в двух языках, то соответствующие тексты должны быть не только равного объема, но и равной насыщенности текста квазисловами.

В заключение отметим, что использование показателя $R_{\text {фон }}$ может быть полезным не только как способ оценки успешности процесса обучения, но и стать толчком к решению некоторых исследовательских задач. Например, представляется продуктивным более подробный анализ индивидуальных данных.

Разный уровень сформированности фонетических навыков во многом объясняется индивидуальными особенностями учащегося (в частности, тем, насколько у него развит речевой слух в его фонетической, фонологической и интонационной разновидностях [Гальскова, Гез, 2009 , с. 275]. Характерной иллюстрацией этого направления исследований могут служить результаты тех наших испытуемых, которые участвовали и в русском, и в английском эксперименте.

Выделим 10 человек, имеющих наилучшие показатели $R_{\text {фон }}$ для английского языка (в среднем для этой группы $\left.R_{\text {фон }}=75,5\right)$. Их средний показатель для русского языка также весьма высок - 71,9. Оба показателя значительно выше среднего уровня. А теперь проделаем то же самое для 10 испытуемых, получивших самые низкие показатели $R_{\text {фон }}$ (среднее по группе - 45,7 для английского языка и 54,5 - для русского). Оба показателя ниже среднего. Таким образом, налицо явная корреляция показателей: лица с высоким $R_{\text {фон }}$ для русского языка имеют высокий показатель и для английского языка.

В этой связи уместно обсудить более общую проблему лингвистической способности, но это потребует более весомого объема экспериментального материала. В любом случае данная проблема остается вне рамок заявленной темы настоящей работы ${ }^{6}$.

\footnotetext{
${ }^{6}$ Некоторые идеи по данной проблеме были высказаны в нашей работе [Василевич, Кудинова, 2020].
} 


\section{Библиографический список / References}

Азимов, Щукин, 1999 - Азимов Э.Г., Щукин А.Н. Словарь методических терминов (теория и практика преподавания языков). СПб., 1999. [Azimov E.G., Shchukin A.N. Slovar metodicheskikh terminov (teoriya i praktika prepodavaniya yazykov) [Dictionary of methodological terms (theory and practice of teaching languages)]. St. Petersburg, 1999.]

Василевич, Кудинова, 2020 - Василевич А.П., Кудинова И.М. Тождественны ли понятия: лингвистическая одаренность и языковая одаренность? // Иностранные языки в школе. 2020. № 2. С. 47-53. [Vasilevich A.P., Kudinova I.M. Are the concepts identical: Linguistic giftedness and language giftedness? Inostrannye yazyki v shkole. 2020. No. 2. Pp. 47-53. (In Rus.)]

Гальскова и др., 2017 - Гальскова Н.Д., Василевич А.П., Акимова Н.В. Методика обучения иностранным языкам. Ростов-на/Д., 2017. [Galskova N.D., Vasilevich A.P., Akimova N.V. Metodika obucheniya inostrannym yazykam [Methodology for teaching foreign languages]. Rostov-on-Don, 2017.]

Гальскова, Гез, 2004 - Гальскова Н.Д., Гез Н.И. Теория обучения иностранным языкам: Лингводидактика и методика: Учеб. пособие для студ. лингв. ун-тов и фак. ин. яз. высш. пед. учеб. заведений. M., 2004. [Galskova N.D., Gez N.I. Teoriya obucheniya inostrannym yazykam: Lingvodidaktika i metodika [Theory of teaching foreign languages: Linguodidactics and methodology]. A textbook for students of linguistic universities and faculties of foreign languages of higher pedagogical educational institutions. Moscow, 2004.]

Реформатский, 1961 - Реформатский А.А. О некоторых трудностях обучения произношению // Русский язык для студентов иностранцев. М., 1961. С. 5-12. [Reformatsky A.A. Some difficulties in learning pronunciation. Russkiy yazyk dlya studentov inostrantsev. Moscow, 1961. Pp. 5-12. (In Rus.)]

Соловова, 2008 - Соловова Е.Н. Методика обучения иностранным языкам: базовый курс. Пособие для студентов пед. вузов и учителей. М., 2008. [Solovova E.N. Metodika obucheniya inostrannym yazykam: bazovyy kurs [Methods of teaching foreign languages: Basic course]. Manual for students of pedagogical universities and teachers. Moscow, 2008.]

Фунтова, 2010 - Фунтова И.Л. Тенденции и основные правила, определяющие место словесного ударения в английском и русском языках // Известия Самарского научного центра Российской академии наук. 2010. Т. 12. № 5 (37). C. 227-232. [Funtova I.L. Trends and basic rules that determine the place of word stress in English and Russian. Izvestia of Samara Scientific Center of the Russian Academy of Sciences. Vol. 12. No. 5(37). Pp. 227-232. (In Rus.)]

Шевякова, 1968 - Шевякова В.Е. Коррективный фонетический курс английского языка. M., 1968. [Shevyakova V.E. Korrektivnyy foneticheskiy kurs angliyskogo yazyka [Corrective phonetic course in English]. Moscow, 1968.]

Штундер, 1981 - Штундер Я.Ч. Пути предупреждения ошибок учащихся в английском произношении. Минск, 1981. [Shtunder Ya.Ch. Puti preduprezhdeniya oshibok uchashchikhsya $\mathrm{v}$ angliyskom proiznoshenii [Ways to prevent learners from making mistakes in English pronunciation]. Minsk, 1981.]

Щукин, 2007 - Щукин А.Н. Обучение иностранным языкам: Теория и практика: Учебное пособие для преподавателей и студентов. 3-е изд. М., 2007. [Shchukin A.N. Obuchenie inostrannym yazykam: Teoriya i praktika [Teaching 
foreign languages: Theory and practice]. A textbook for teachers and students. 3rd ed. Moscow, 2007.]

Щукин, 2008 - Щукин А.Н. Лингводидактический энциклопедический словарь. M., 2008. [Shchukin A.N. Lingvodidakticheskiy entsiklopedicheskiy slovar [Linguodidactic Encyclopedic Dictionary]. Moscow, 2008.]

Статья поступила в редакцию 07.08.2020

The article was received on 07.08.2020

O6 авторе / About the author

Василевич Александр Петрович - доктор филологических наук; профессор кафедры лингводидактики, Московский государственный областной университет

Alexander P. Vasilevich - Dr. Phil. Hab.; Professor at the Department of Linguodidactics, Moscow Region State University

E-mail: basilevich@mail.ru 